Ciência Florestal, Santa Maria, v. 23, n. 1, p. 183-191, jan.-mar., 2013

ISSN 0103-9954

\title{
O CUSTO SOCIAL DO DESMATAMENTO DA AMAZÔNIA BRASILEIRA: O CASO DA CASTANHA-DO-BRASIL (Bertholletia excelsa)
}

\section{THE SOCIAL COST OF DEFORESTATION OF THE BRAZILIAN AMAZON: THE CASE OF THE BRAZILIAN CHESTNUT (Bertholletia excelsa)}

\author{
Humberto Angelo ${ }^{1}$ Raquel Souza Pompermayer ${ }^{2}$ Alexandre Nascimento de Almeida ${ }^{3}$ \\ José Mauro Magalhães Ávila Paz Moreira ${ }^{4}$
}

\section{RESUMO}

Este trabalho trata do desmatamento na Amazônia brasileira com ênfase no custo social imposto à nação pela redução e perda da base florestal, em especial da castanha, um dos principais produtos não madeireiros da floresta, no período de 1998 a 2008. Para medir os custos sociais do desmatamento que recaem sobre os produtores e consumidores de castanha-do-brasil, utilizou-se o conceito de excedente econômico de Marshall. O custo social médio anual estimado foi da ordem de 11,6 milhões de reais, recaindo, em média, $63 \%$ desses custos sobre os produtores e $37 \%$ sobre os consumidores. Portanto, todos perdem com os danos causados à base florestal e ao ecossistema da floresta tropical.

Palavras-chave: custo social; desmatamento; castanha-do-brasil; Amazônia.

\begin{abstract}
In this article, it is studied the deforestation of 'castanha-do-brasil' (Bertholletia excelsa) from the Brazilian tropical rainforest with emphasis on the valuation of social costs imposed on society by the reduction and the loss of forest cover from 1998 to 2008. To measure the social costs, the concept used was of Marshall economic surplus, which measures the level of welfare consumers and producers. From 1998 to 2008, the estimated average social costs were of R $\$ 11.6$ million per year. The social costs falling $63 \%$ on producers and $37 \%$ on consumers. In conclusion, both, supply and demand, lose with damages in the Brazilian tropical rainforest.
\end{abstract}

Keywords: social costs; deforestation; Brazilian nut; Amazonian.

\section{INTRODUÇÃO}

A intensificação das atividades socioeconômicas, aliada às práticas inadequadas de manejo dos recursos florestais, tem provocado a degradação das florestas, resultando em perda de biodiversidade e alterações no ciclo hidrológico, colaborando assim com as mudanças do clima.

Entre 2000 e 2005, todos os países da América do Sul, à exceção do Chile e do Uruguai, registraram uma taxa de perda de superfície florestal de $0,50 \%$ ao ano, enquanto a perda da superfície florestal mundial foi de $0,18 \%$ ao ano (FAO, 2009).

$\mathrm{O}$ desflorestamento resultante da extração intensa dos recursos madeireiros e das mudanças no uso da terra, para cultivos anuais e pastagens, tem exercido fortes pressões sobre os produtos florestais não madeireiros, particularmente sobre a castanha-do-brasil (Bertholletia excelsa, H.B.K.) (KITAMURA e MÜLLER, 1984; SANTANA e KHAN, 1992; HOMMA et al., 1996). Na América Latina, a produção extrativa não madeireira é

1. Engenheiro Florestal, Dr., Professor do Departamento de Engenharia Florestal, Faculdade de Tecnologia, Universidade de Brasília, Caixa Postal, 04357, Asa Norte, CEP 70919-970, Brasília (DF). humb@unb.br

2. Engenheira de Produção, Msc., Doutoranda em Ciências Florestais, Universidade de Brasília, Caixa Postal, 04357, Asa Norte, CEP 70919-970, Brasília (DF). rasop97@yahoo.com

3. Engenheiro Florestal, Dr., Professor da Faculdade de Planaltina, Universidade de Brasília, Campus de Planaltina, Área Universitária 01, Vila Nossa Senhora de Fátima, CEP 73350-010, Planaltina (DF). alexfloresta@pop.com.br

4. Engenheiro Florestal, Dr., Pesquisador da EMBRAPA/Florestas, Estrada da Ribeira, Km 111, Caixa Postal 319, CEP 83411-000, Colombo (PR). josemauro@cnpf.embrapa.br

Recebido para publicação em 22/04/2010 e aceito em 4/10/2011 
destinada à subsistência de comunidades locais, embora alguns produtos sejam comercializados no mercado nacional e internacional.

O extrativismo da castanha-do-brasil é uma importante fonte de rendimento para os grupos indígenas da Bolívia, Brasil e Peru. Nesses países, a cadeia de suprimentos da castanha-do-brasil emprega diretamente cerca de 15.000 pessoas. Também, esse produto representa $45 \%$ das exportações relacionadas às florestas da Bolívia, superando as exportações de todos os produtos madeireiros e contribuindo com mais de 70 milhões de dólares anualmente para a sua economia (CIFOR, 2008).

Atualmente, oBrasil detém $37 \%$ daprodução mundial, ficando à frente do Peru, que contribui com $13 \%$, e atrás da Bolívia, que é responsável por $50 \%$ da produção mundial (TONINI, 2007; MARTINS et al., 2008). A produção extrativa brasileira da castanha concentra-se principalmente no Estado do Amazonas, responsável por 30,2 \% da produção média nacional, no período de 1998 a 2008. Nesse período, os Estados do Acre e do Pará contribuíram com cerca de, $28,4 \%$ e $23,9 \%$ da produção média nacional, respectivamente. Os Estados de Rondônia, Mato Grosso, Roraima e Amapá totalizaram 17,45 \% da produção média nacional, no período de 1998 a 2008 (IBGE, 2009).

O desflorestamento promove a depredação dos castanhais, em virtude de sua substituição por outras atividades, como a pecuária e o cultivo da terra, além da exploração predatória da madeira. A degradação dos castanhais, apontando para a exaustão desse recurso, impõe um custo à sociedade. Esse custo pode ser compreendido como uma redução no nível de bem-estar social, decorrente da diminuição da oferta do produto e do aumento do preço.

Considerandoaimportância socioeconômica dos recursos florestais e a carência de medidas de manejo sustentável nas áreas de abrangência da Amazônia Legal, constata-se a necessidade de mecanismos para mensurar, em termos monetários, os impactos sociais da depredação desses recursos.

Neste estudo, propõe-se especificamente: estimar os custos sociais do desflorestamento decorrente do manejo não sustentável da castanhado-brasil; verificar a distribuição dos custos sociais, com a depredação da castanha, entre produtores e consumidores; e dimensionar as perdas dos benefícios econômicos gerados pela comercialização da castanha, em razão do desmatamento.

\section{METODOLOGIA}

\section{Referencial teórico}

A quantificação dos benefícios e dos custos sociais advindos de mudanças tecnológicas, assim como sua distribuição entre os diferentes grupos de interesse (consumidores e produtores), é de relevante interesse. Esses benefícios referem-se aos ganhos de comércio e são mensurados por meio de um excedente econômico, que é uma medida de bem-estar dos participantes do mercado.

Há um preço máximo que consumidores estão dispostos a pagar por dada quantidade de um bem, o qual é representado por pontos ao longo de sua curva de demanda, correspondendo aos valores da disposição a pagar de todos os compradores. Quando a disposição a pagar dos compradores é superior ao preço que eles realmente pagam, estes recebem um ganho - denominado excedente do consumidor. Esse excedente é uma medida da diferença entre o sacrifício que o comprador estaria disposto a fazer para obter um bem e o preço que ele tem de pagar em troca. Marshall propõe que o excedente do consumidor equivale à área do triângulo abaixo da curva de demanda e acima da linha de preço (CURRIE et al., 1971; HACKETT, 2006).

Por outro lado, os vendedores recebem um ganho simétrico, chamado excedente do produtor, quando o preço de mercado excede os custos que precisam ser cobertos para que se tenha valor de venda. Marshall elaborou o conceito de excedente do produtor para formalizar a noção de que tanto o vendedor como o comprador podem receber algum tipo de excedente numa transação. $\mathrm{O}$ excedente do produtor mede o seu bem-estar e está definido como a área acima da curva de oferta e abaixo da linha do preço (CURRIE et al., 1971; HANLEY e SPASH, 1993; HACKETT, 2006).

No Brasil, o conceito de excedente econômico de Marshall tem sido amplamente utilizado para quantificação dos benefícios e dos custos sociais advindos das variações de produtividade de um recurso natural, associadas a mudanças tecnológicas. Santana e Khan (1992) utilizaram o conceito de excedente econômico para estimar o custo social da depredação dos castanhais no Estado do Pará, assim como sua distribuição entre produtores e consumidores nacionais. Também Ângelo (1998) utilizou a abordagem do excedente econômico para estimar o custo social da perda da base florestal decorrente das exportações 
de madeiras da floresta amazônica. Moreira (2004) estimou o custo social da depredação da castanhado-brasil em virtude do desmatamento da Amazônia brasileira, e Silva et al. (2006) determinaram os retornos sociais para os produtores e consumidores decorrentes de novas tecnologias para o cultivo do açaí no Estado do Pará.

\section{Referencial analítico}

Uma abordagem simples, que tem por base o conceito de excedente econômico de Marshall, foi inicialmente proposta por Lindner e Jarrett (1978) para quantificação e distribuição dos benefícios entre produtores e consumidores. $\mathrm{Na}$ estimativa dos benefícios, a abordagem considera a forma do deslocamento da curva de oferta, em resposta à adoção de um processo de inovação tecnológica. Para isso, o modelo assume uma aproximação linear para as curvas de oferta e de demanda e um deslocamento divergente da curva de oferta.

A distância vertical entre as curvas de oferta aumenta à medida que aumenta a quantidade fornecida, implicando maiores reduções nos custos médios para os produtores marginais (que adotaram novas tecnologias). A Figura 1 apresenta o modelo proposto por Lindner e Jarrett (1978), em que $\mathrm{D}_{0}$ representa a demanda por um determinado produto homogêneo e $\mathrm{S}_{0}$ e $\mathrm{S}_{1}$ representam, respectivamente, a oferta do produto antes e após a inovação tecnológica. O equilíbrio inicial é dado por $\mathrm{P}_{0}$ e $\mathrm{Q}_{0}$ após o deslocamento, o novo equilíbrio é estabelecido em $P_{1}$ e $Q_{1}$.

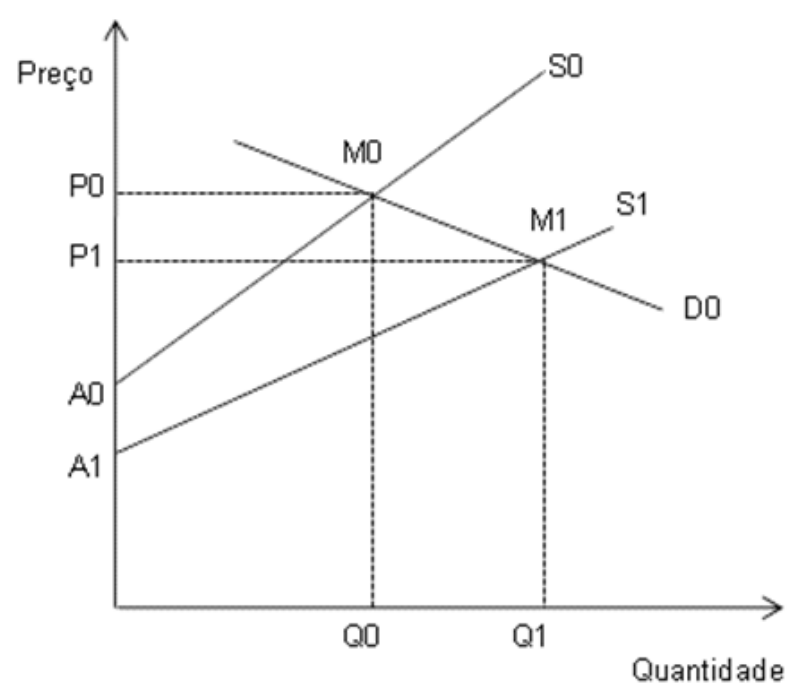

FIGURA 1: Modelo de Lindner e Jarret (1978)

FIGURE 1: Lindner e Jarret (1978) model.
$\mathrm{O}$ benefício total é mensurado pela área $A_{1} M_{1} M_{0} A_{0}(X)$, enquanto as mudanças no excedente do consumidor são determinadas pela área $\mathrm{P}_{0} \mathrm{M}_{0} \mathrm{M}_{1} \mathrm{P}_{1}(\mathrm{Y})$, e o beneficio do produtor resulta da diferença entre as áreas $\mathrm{X}$ e $\mathrm{Y}$. Os autores citados verificaram que os benefícios são altamente sensíveis à natureza do deslocamento da curva de oferta, em determinadas condições de elasticidades da oferta e da demanda.

Rose(1980)identificou algumas fragilidades do modelo, além de fornecer uma alternativa simplificada para a estimativa dos benefícios sociais resultantes de inovações tecnológicas (Figura 2). Segundo esse autor, uma das limitações do modelo está na estimativa dos interceptos, uma vez que Lindner e Jarrett (1978) assumiram que os interceptos $A_{0}$ e $A_{1}$ poderiam ser estimados independentemente de $\mathrm{S}_{0}$ e $\mathrm{S}_{1}$ Ao contrário do modelo proposto por Lindner e Jarrett (1978), que é aplicado somente quando as curvas de oferta e de demanda são lineares, o modelo proposto por Rose (1980) sugere uma dobra na curva de oferta abaixo de $M_{0}$. A abordagem simplificada, apresentada na Figura 2, consiste em estimar separadamente a área $\mathrm{M}_{0} \mathrm{M}_{1} \mathrm{~B}_{1}(\mathrm{X})$ e em especificar o valor de $\mathrm{M}_{0} \mathrm{~B}_{1}$. O benefício social total é obtido pela soma entre as áreas $M_{0} M_{1} B_{1}(X)$ e $A_{0} M_{0} B_{1} A_{1}(Y)$. Ao contrário do modelo proposto por Lindner e Jarrett (1978), a nova abordagem não apresenta sensibilidade às mudanças na elasticidade, uma vez que $X$ é relativamente pequeno e $\mathrm{Y}$ não depende desta.

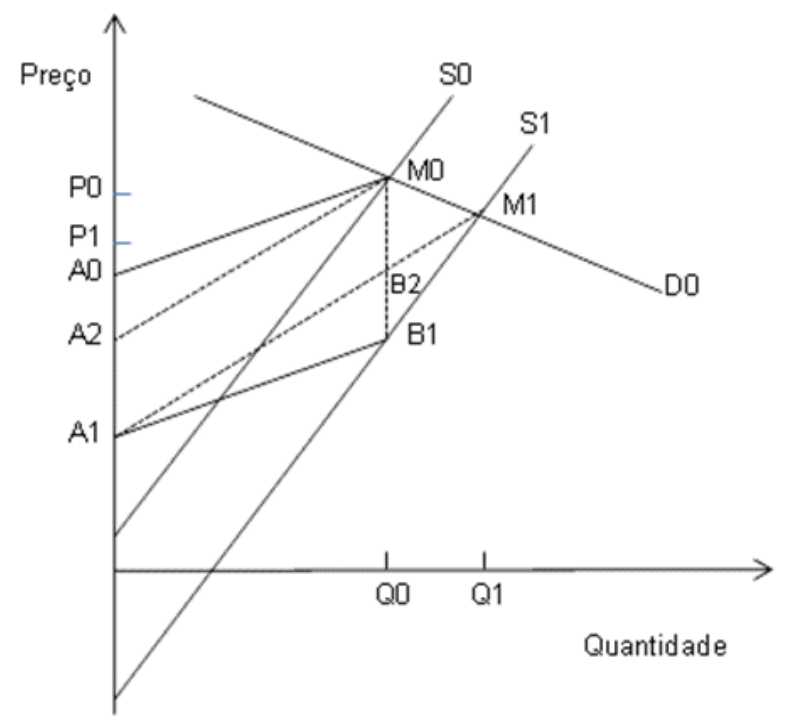

FIGURA 2: Modelo de Rose (1980).

FIGURE 2: Rose (1980) model. 
Norton e Davis (1981) salientam que, na estimativa dos benefícios sociais, as diferentes concepções nas formas das curvas de oferta não são tão relevantes quanto à natureza e à magnitude de seu deslocamento. A dimensão do deslocamento da curva da oferta é fator determinante na quantificação dos benefícios sociais líquidos. Também os autores citados destacam que a elasticidade da demanda é igualmente importante na estimativa dos benefícios de uma nova tecnologia.

Santana e Khan (1992) adaptaram o modelo desenvolvido por Lindner e Jarret (1978) e aperfeiçoado por Rose (1980) e Norton e Davis (1981) para estimar custos sociais gerados pela depredação da castanha no Estado do Pará. Conforme ilustrado na Figura 3, Santana e Khan (1992) afirmam que a exploração extrativista desloca a curva de oferta de $\mathrm{S}_{1}$ para $\mathrm{S}_{0}$. Portanto, o novo equilíbrio ocorre no ponto $\mathrm{A}$, onde preços maiores e quantidades menores são praticados, em comparação com a situação inicial de equilíbrio.

Na Figura 3, os custos sociais resultantes da depredação da castanha estão representados pela área formada pelo polígono $\mathrm{ABCE}$, entre as duas curvas de oferta $\left(\mathrm{S}_{0}\right.$ e $\left.\mathrm{S}_{1}\right)$ e abaixo da curva de demanda (D). Para determinação dessa área, assim como da parcela dos custos que recaem sobre os produtores e consumidores, Santana e Khan (1992) propuseram as

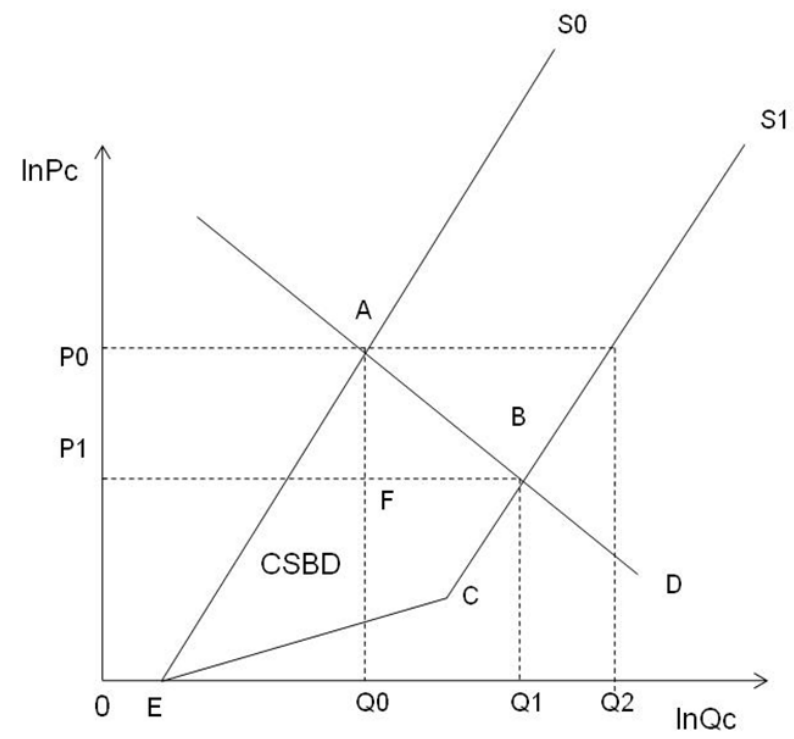

FIGURA 3: Modelo aperfeiçoado para estimativa do custo social total (CSBD), adaptado de Santana e Khan (1992).

FIGURE 3: Improved model to estimate the total social cost (CSBD), adapted from Santana e Khan (1992). seguintes formulações:

$\mathrm{Z \eta})$

Custo Social Total $(\mathrm{CSBD})=0,5 \mathrm{KP}_{0} \mathrm{Q}_{0}(1+$

Custo Social do Consumidor (CC) = $\mathrm{ZP}_{0} \mathrm{Q}_{0}(1+0,5 \mathrm{Z \eta})$

Custo Social do Produtor $=$ CSBD - CC

em que K é o deslocador da curva de oferta, medido pela mudança proporcional na produção, dividida pela elasticidade da oferta $(\varepsilon)$ :

$$
\begin{aligned}
& \mathrm{K}=\left|\left(1-\mathrm{Q}_{0} / \mathrm{Q}_{2}\right) / \varepsilon\right| \\
& \mathrm{P}_{0} \text { e } \mathrm{Q}_{0} \text { são os valores médios dos preços e }
\end{aligned}
$$
das quantidades comercializadas no equilíbrio após a depredação, e $\mathrm{P}_{1}$ e $\mathrm{Q}_{1}$ são os preços e as quantidades comercializadas no equilíbrio antes da perda da base florestal. Os parâmetros $\eta$ e $\varepsilon$ são, respectivamente, as elasticidades da demanda e da oferta em relação a preço, e $\mathrm{Q}_{2}$ é igual à média histórica de produção de castanha. Santana e Khan (1992) propuseram a seguinte expressão para obtenção de Z:

$$
\mathrm{Z}=\mathrm{K} \varepsilon /(\eta+\varepsilon)
$$

Para efeito de análise, considerou-se a hipótese de que, quanto mais inelástica a oferta em relação a preço em comparação com a demanda em relação ao preço, maior a parcela de custo social que recai sobre os produtores regionais. Gopalakrishnan et al. (2004) evidenciam que em regiões extrativas, onde predomina a agricultura, existe uma competitividade na alocação do tempo de mão de obra entre a agricultura e a atividade extrativa de subsistência. Esse aspecto é responsável pelas respostas inelásticas da oferta em relação a preço. Os referidos autores também constataram que, geralmente, a demanda por produtos não madeireiros de subsistência das florestas tropicais do Sri Lanka apresenta resposta inelástica em relação a preço, com coeficiente de elasticidade-preço da demanda de não madeireiros da ordem de - 0,84. Esse aspecto mostra que eles são parte essencial do estilo de vida rural, desempenhando importantes funções em domicílios rurais, como, por exemplo, as plantas medicinais e os alimentos sazonais. Isso significa que, quanto mais essencial ou necessário for um produto aos consumidores, menos sensíveis serão estes às variações de preços (MENDES, 2004).

\section{Fonte de dados}

As estimativas dos custos sociais da depredação da castanha-do-brasil, nos Estados do Amazonas, Acre, Pará e Mato Grosso, foram obtidas a partir de dados secundários disponíveis na base de dados do Sistema IBGE de Recuperação Automática 
(SIDRA), do Instituto Brasileiro de Geografia e Estatística (IBGE). Os dados utilizados referem-se às seguintes variáveis: quantidade anual produzida $\mathrm{e}$ valor da produção anual. As estimativas compreendem o período de 1998 a 2008, no qual a evolução do preço da castanha-do-brasil foi obtida por meio da razão entre o valor da produção e a quantidade produzida. Os preços foram deflacionados para valores de 2008, pelo Índice de Preços no Atacado-Disponibilidade Interna (IPA-DI), da Fundação Getúlio Vargas.

Para determinação do custo social da depredação da castanha-do-brasil, utilizaram-se os seguintes parâmetros: elasticidade da demanda em relação a preço $(\eta)$, elasticidade da oferta em relação a preço $(\varepsilon)$ e quantidade média de castanha comercializada no período estudado $\left(\mathrm{Q}_{2}\right)$.

Os valores adotados para as elasticidades da oferta e da demanda em relação a preço foram obtidos do estudo realizado por Moreira (2004), para determinação do custo social da depredação da castanha, nos Estados do Pará, Amazonas e Acre. Nesse estudo, esse autor obteve as elasticidades por meio da estimativa das funções de demanda e de oferta da castanha. A extensão da área desmatada nesses Estados foi uma das variáveis consideradas na função de oferta. A adoção das elasticidades determinadas por Moreira (2004) tem como principal restrição o horizonte de tempo, uma vez que as elasticidades tendem a aumentar no tempo. Ou seja, as elasticidades calculadas no longo prazo são maiores que as de curto prazo, visto que as variações das quantidades demandadas e ofertadas e dos preços no longo prazo são maiores. Nesse estudo, adotaramse coeficientes determinados no período de 1988 a 2001, enquanto o horizonte de tempo considerado é de 1998 a 2008.

Foram determinados os valores do deslocador proporcional vertical da curva de oferta (K), os custos sociais totais, assim como as parcelas de custos que recaem sobre os consumidores e produtores no período analisado. Determinouse, também, o valor percentual do custo social em relação ao valor da produção comercializada, como um indicador da perda do benefício econômico gerado pela comercialização da castanha, em razão do desmatamento.

\section{RESULTADOS E DISCUSSÃO}

O custo social total, referente à perda da base florestal, foi estimado para os Estados do Amazonas, Pará, Acre e Mato Grosso. Para isso, foram utilizados os preços e as quantidades da castanha-do-brasil comercializada nesses Estados no período de 1998 a 2008. Os valores adotados para as elasticidades da oferta e da demanda em relação a preço foram de 0 , 2080 e $-0,8508$, respectivamente.

Na Tabela 1 estão determinados os valores do deslocador proporcional da curva de oferta $(\mathrm{K}) \mathrm{em}$ termos percentuais, o custo social total, as parcelas de custo social atribuídas aos produtores regionais e aos consumidores nacionais, assim como o valor percentual do custo social em relação ao valor da produção comercializada.

TABELA 1: Determinação do custo social e de seus impactos sobre a sociedade e a perda dos benefícios da comercialização da castanha (em 1.000 R \$ de 2008).

TABLE 1: Determining the social costs and their impacts on the society and the loss of benefits from the commercialization of chestnut (in 1000 US\$).

\begin{tabular}{|c|c|c|c|c|c|c|}
\hline \multirow[b]{2}{*}{ Período } & \multirow{2}{*}{$\begin{array}{l}\text { Deslocamento da } \\
\text { curva de oferta } \\
\text { (K) }(\%)\end{array}$} & \multirow{2}{*}{$\begin{array}{l}\text { Custo } \\
\text { social total } \\
\text { (CT) }\end{array}$} & \multicolumn{2}{|c|}{ Distribuição do custo social } & \multirow{2}{*}{$\begin{array}{c}\text { Valor } \\
\text { comercializado da } \\
\text { Produção (VP) }\end{array}$} & \multirow{2}{*}{$\begin{array}{c}\mathrm{CT} / \mathrm{VP} \\
(\%)\end{array}$} \\
\hline & & & $\begin{array}{c}\text { Consumidores } \\
\text { nacionais }\end{array}$ & $\begin{array}{c}\text { Produtores } \\
\text { nacionais }\end{array}$ & & \\
\hline 1998 & 90,63 & $14.884,16$ & $5.462,27$ & $9.421,89$ & $28.526,47$ & 52,18 \\
\hline 1999 & 11,76 & $1.854,61$ & 721,51 & $1.133,10$ & $30.933,68$ & 6,00 \\
\hline 2000 & 27,36 & $4.837,32$ & $1.858,66$ & $2.978,66$ & $33.812,50$ & 14,31 \\
\hline 2001 & 47,60 & $13.456,55$ & $5.091,26$ & $8.365,29$ & $52.372,61$ & 25,69 \\
\hline 2002 & 42,47 & $9.643,89$ & $3.662,80$ & $5.981,09$ & $42.406,04$ & 22,74 \\
\hline 2003 & 69,82 & $12.468,55$ & $4.642,02$ & $7.826,53$ & $31.985,03$ & 38,98 \\
\hline 2004 & 17,19 & $3.024,10$ & $1.171,35$ & $1.852,76$ & $34.195,22$ & 8,84 \\
\hline 2005 & 68,90 & $21.043,80$ & $7.839,67$ & $13.204,13$ & $54.779,20$ & 38,42 \\
\hline 2006 & 25,27 & $6.431,03$ & $2.475,07$ & $3.955,96$ & $48.839,05$ & 13,17 \\
\hline 2007 & 69,90 & $18.314,49$ & $6.818,03$ & $11.496,46$ & $46.917,54$ & 39,04 \\
\hline 2008 & 88,04 & $21.629,88$ & 7.951,77 & $13.678,10$ & $42.836,00$ & 50,49 \\
\hline Média & 90,63 & $11.598,94$ & $4.335,86$ & $7.263,09$ & $40.691,21$ & 28,50 \\
\hline
\end{tabular}


O custo social total médio de depredação da castanha-do-brasil, decorrente da perda da base florestal, foi estimado em $\mathrm{R} \$ 11,59$ milhões no período de 1998 a 2008, atingindo valor máximo de $\mathrm{R} \$ 21,63$ milhões em 2008. Quanto à distribuição desse custo entre produtores e consumidores, os resultados indicam um valor médio de R\$ 4,33 milhões para os consumidores e R \$ 7,26 milhões para os produtores. Isso significa que a parcela do custo social da depredação da castanha que incide sobre os consumidores é, em média, de 37,4\% do custo total, ao passo que a parcela que recai sobre os produtores é da ordem de $62,6 \%$ do custo total.

Os resultados obtidos mostram que, quanto mais inelástica a oferta em relação a preço em comparação com a demanda em relação a preço, maior é a parcela do custo social da depredação da castanha que incide sobre os produtores regionais. Entretanto, eles divergem dos encontrados por Santana e Khan (1992), que apontam maior incidência do custo social, decorrente da depredação da castanha, sobre os consumidores nacionais $(81,41 \%)$. Esse resultado foi influenciado pelos valores elásticos da demanda e oferta em relação a preço, que foram da ordem de $-2,61$ e 2,10, respectivamente.

O comportamento elástico da oferta e da demanda da castanha em relação a preço, constatado por Santana e Khan (1992), não é condizente com a dinâmica de sua comercialização e de sua exploração, que praticamente ocorre na forma extrativa. Do lado da oferta, esses autores estimaram um coeficiente da ordem de 2,10 para a elasticidade-preço da oferta, refletindo um comportamento elástico da oferta da castanha em relação a preço. No entanto, como a coleta da castanha é realizada exclusivamente por extrativismo, com a depredação da castanha, os custos de extração aumentam, assim como a migração de mão de obra para outras atividades (por exemplo, agricultura). Consequentemente, o extrativismo da castanha, que antes era a principal fonte de renda para muitas comunidades locais, passa a ser fonte de renda complementar. Isso, por sua vez, deixa a oferta da castanha mais rígida diante das variações dos preços, ou seja, a oferta da castanha torna-se mais inelástica com o esgotamento da possibilidade de sua obtenção por extrativismo.

Do lado da demanda, quanto maior a disponibilidade de bons substitutos para um produto específico, maior será sua elasticidade-preço da demanda (MENDES, 2004). Silva et al. (2006) constataram que melhorias tecnológicas associadas à presença da agroindústria tornaram a demanda por produtos processados de açaí substancialmente elástica em comparação com a demanda pelo produto in natura. O coeficiente de elasticidadepreço da demanda foi da ordem de $-4,24$, indicando que, para variações de $1 \%$ no preço do açaí, a quantidade demandada irá variar $4,24 \%$ em sentido contrário. A resposta elástica da demanda de açaí em relação a preço também traduz o comportamento dos consumidores em relação aos produtos substitutos e complementares potenciais para o açaí. Silva e Silva (2006) apontam que 37,5\% dos consumidores substituem o açaí por outras frutas, ao passo que $31,4 \%$ o substituem por sucos diversos e $22 \%$ consomem bacaba como substituto do açaí.

$\mathrm{Na}$ região de estudo, a comercialização de castanha é base de sobrevivência de muitas comunidades indígenas. Particularmente, no Estado do Mato Grosso, estudos realizados por Souza et al. (2008) constataram a influência dessas comunidades nas estruturas de mercado ao longo da cadeia produtiva Dessa forma, a comercialização da castanha in natura é realizada pelos índios individualmente e por associações que compram a produção dos associados e revendem aos agentes intermediários de outros estados. Segundo os autores citados, essa estrutura de mercado, baseada em transações comerciais entre o produtor indígena e o varejo e entre o produtor indígena e o agente intermediário, caracteriza um oligopólio. Assim, a comercialização da castanha é realizada por meio de um arranjo caracterizado por um pequeno número de empresas dominando o mercado e ofertando um produto homogêneo (in natura), com poucos substitutos para ela no mercado brasileiro.

Ao contrário do açaí, cujo processamento industrial lhe conferiu grande número de utilizações, além da disponibilidade de substitutos para ele no mercado, a castanha é produto comercializado essencialmente in natura. Portanto, trata-se de um produto que não possui bons substitutos no mercado brasileiro; assim, é de se esperar menores respostas dos consumidores nacionais às variações de preço, ou seja, mais inelástica é a sua demanda. Ressaltese, assim, que o comportamento elástico da demanda de castanha $(\eta=-4,61)$, verificado por Santana e Khan (1992), não é coerente com as características do mercado brasileiro da castanha.

Na Tabela 1, também, estão determinados os percentuais de comprometimento dos benefícios econômicos da comercialização da castanha, em razão dos custos sociais do desmatamento, no 
período de 1998 a 2008. Os resultados indicam que o custo social resultante do desflorestamento compromete, em média, $28,5 \%$ dos retornos econômicos gerados pela comercialização da castanha nesse período. Em 2007, o custo social decorrente do desflorestamento comprometeu $39 \%$ dos benefícios totais gerados pela comercialização da castanha nos Estados analisados. Em 2008, verificou-se maior comprometimento dos benefícios da comercialização da castanha, quando o custo social do desmatamento foi responsável pela perda de $50 \%$ desses benefícios. As menores perdas de benefícios da comercialização da castanha nos Estados analisados foram verificadas nos anos de 1999 e 2004, com percentuais de apenas $6 \%$ e $8,8 \%$ do valor da produção, respectivamente.

No Estado do Acre, por exemplo, os retornos gerados pela produção extrativa vegetal, em 2007, foram da ordem de R\$ 32,9 milhões; a castanha contribuiu com cerca de, 36,8\% desse valor (R\$ 12,1 milhões), seguida pela extração madeireira, que representou $35,9 \%$ do valor da produção (R\$ 11,8 milhões). Destaque-se que, em 2007, os benefícios econômicos da produção extrativa vegetal representaram, aproximadamente, $0,6 \%$ valor do PIB do Acre, dos quais $0,21 \%$ corresponderam à contribuição da castanha. Em termos de custos sociais decorrentes do desmatamento, constatamse, em 2007, perdas de benefícios da ordem de R $\$$ 4,7 milhões, dos quais 1,76 milhões correspondem às perdas para os consumidores e 2,97 milhões para os consumidores.

Nos Estados do Pará e Mato Grosso, os benefícios econômicos da produção extrativa vegetal foram de 1,24 bilhões de reais e 265,6 milhões de reais, respectivamente, em 2007. No Pará, os benefícios gerados pela comercialização da produção extrativa vegetal corresponderam a cerca de, 2,5\% de seu PIB, em 2007. No entanto, o percentual de benefícios econômicos da castanha correspondeu a apenas $0,66 \%$ (R\$ 8,1 milhões) do valor da produção extrativa vegetal comercializada naquele ano, enquanto os retornos econômicos da extração madeireira representaram, significativamente, 83,3 \% desse valor. No Mato Grosso, a produção extrativa de castanha representou, em 2007, apenas $0,35 \%$ ( R \$ 925 mil) do valor da produção extrativa vegetal comercializada naquele ano, ao passo que a comercialização da madeira em tora representou $79,7 \%$ desse valor. Nesses Estados, verifica-se uma baixa rentabilidade da produção extrativa da castanha em comparação com a exploração madeireira. Esse aspecto reflete o esgotamento da capacidade produtiva do ecossistema com a depredação da castanha pelo desmatamento e com o avanço de outras atividades econômicas (agricultura e pecuária).

Por fim, o desmatamento da região amazônica resulta em impactos na forma de custo social, comprometendo os benefícios gerados pela comercialização da castanha. Esses custos recaem expressivamente sobre as populações de comunidades que dependem da comercialização da castanha como principal fonte de renda. Nessas comunidades, a extração da castanha de subsistência faz parte do estilo de vida rural, de modo que não há alocação competitiva de mão de obra entre coleta da castanha e agricultura de subsistência. Como o principal custo de extração é o custo de oportunidade do tempo de alocação da mão de obra, essas populações permanecem rígidas no que se refere às variações de preço. Esse aspecto caracteriza uma oferta inelástica a preço e, consequentemente, essas populações são as que mais sofrem com os impactos do custo social da depredação da castanha pelo desmatamento.

\section{CONCLUSÕES}

A quantificação dos custos utilizando um modelo linear simplificado, formulado com base no conceito do excedente do produtor e do consumidor, forneceu uma estimativa da distribuição dos custos sociais totais coerentes com valores de elasticidades utilizados. Esse aspecto constata a relevância da natureza e da magnitude do deslocamento da curva de oferta.

O custo social médio da depredação da castanha-do-brasil, decorrente do desmatamento da Amazônia brasileira, foi estimado em R\$ 11,59 milhões no período de 1998 a 2008, o equivalente a $28,5 \%$ dos benefícios gerados pela comercialização da castanha nesse período.

Quanto à distribuição do custo social total entre os consumidores e produtores nacionais, constata-se que ele incide significativamente sobres os produtores: aproximadamente $63 \%$, em média, no período de 1998 a 2008.

O maior comprometimento dos benefícios da comercialização da castanha pelo desmatamento da Amazônia brasileira foi verificado em 1998, quando o custo social do desmatamento foi responsável pela perda de 52,18\% desses benefícios.

Em contrapartida, as menores perdas de 
benefícios da comercialização da castanha, em virtude do desmatamento da Amazônia brasileira, foram verificadas em 1999 e 2004, comprometendo apenas $6,0 \%$ e $8,8 \%$ do valor de sua produção, respectivamente.

\section{REFERÊNCIAS BIBLIOGRÁFICAS}

ANGELO, H. Custo social das exportações brasileiras de madeiras tropicais na floresta amazônica. Revista Árvore, Viçosa, v. 22, n. 4, p. 495-501, 1998.

CIFOR. Best Brazil nut practice in Bolivia. Bogor (Indonesia), Center for International Forestry Research, 2009. Disponível em: <http://www.cifor. cgiar.org/Publications/Corporate/NewsOnline/ NewsOnline43/brazil_nut.ht $>$. Acesso em: $20 \mathrm{dez}$. 2009.

CURRIE, J. M. ; MURPHY, J. A.; SCHMITZ, A. The concept of economic surplus and its use in economic analysis. The Economic Journal, v. 81, n. 324, p. 741-799, 1971. Disponível em: < http:// www.jstor.org/stable/2230317 >Acesso em: 26 jan. 2010.

FAO. State of the world's forests 2009. Roma (Itália), Food and Agriculture Organization of the United Nations, 2009. Disponível em: $<$ http://www. fao.org/docrep/011/i0350e/i0350e00.htm> Acesso em: 08 dez. 2009.

GOPALAKRISHNAN, C. et al. Estimating the demand for non-timber forest products among rural communities: a case study from the Sinharaja Rain Forest region, Sri Lanka. Agroforestry Systems, v. 65 , p. 13-22, 2005, Disponível em: <http://www. springerlink.com/content/t02227p72nj82758/ > Acesso em: 19 jan. 2010.

HACKETT, S. C. Environmental and natural resources economics: theory, policy and the sustainable society. Londres: M. E. Sharpe, 2006. $524 \mathrm{p}$.

HANLEY, N.; SPASH, C. L. Cost-benefit analysis and the environment. London: Ed. Edward Elgar, 1993. $278 \mathrm{p}$.

HOMMA, A. K. O. et al. Razões de risco e rentabilidade na destruição de recursos florestais: o caso de castanhais em lotes de colonos no Sul do Pará. Revista Econômica do Nordeste, Fortaleza, v. 27, n. 3, p. 515-535, 1996.

IBGE. Produção da Extração Vegetal e da Silvicultura. Instituto Brasileiro de Geografia e Estatística, 2009. Disponível em: <http:// www.sidra.ibge.gov.br/bda/acervo/acervo2.asp? $\mathrm{e}=\mathrm{v} \& \mathrm{p}=\mathrm{VS} \& \mathrm{z}=\mathrm{t} \& \mathrm{o}=18>$. Acesso em: 14 nov. 2009. KITAMURA, P. C.; MULLER, C. H. Depredação e preservação dos castanhais nativos; o caso de Marabá. In: SIMPÓSIO DO TRÓPICO ÚMIDO, 1984, Belém. Anais... Belém: Embrapa-Cpatu, 1984. v. 6. p. 277-285.

LINDNER, P. K.; JARRET, F. G. Supply shifts and the size of research benefits. American Journal of Agricultural Economics, v. 60, n. 1, p. 4858, 1978. Disponível em: <http://www.jstor.org/ stable/1240160> Acesso em: 24 mai. 2009.

MARTINS, L.; SILVA, G. Z. P.; SILVEIRA, B. C. Produção e comercialização da castanha do brasil (Bertholletia excelsa, H.B.K) no Estado do Acre - Brasil, 1998-2006. In: CONGRESSO DA SOCIEDADE BRASILEIRA DE ECONOMIA, ADMINISTRAÇÃO E SOCIOLOGIA RURAL, 2008, Rio Branco. Disponível em: <http://www. sober.org.br/palestra/9/425.pdf > Acesso em: 24 jan. 2010.

MENDES, J. T. G. Economia: fundamentos e aplicações. São Paulo: Pearson Prentice Hall, 2004. $309 \mathrm{p}$.

MOREIRA, J. M. A. P. O custo social do desmatamento da Amazônia brasileira. 2004. 46 f. Dissertação (Mestrado em Ciências Florestais) - Universidade de Brasília. Brasília, 2004.

NORTHON, G. W.; DAVIS, J. S. Evaluating returns to agricultural research: a review. American Journal of Agricultural Economics, Agricultural \& Applied Economics Association, v. 63, n. 4, p. 685-699, 1981. Disponível em: <http://www.jstor. org/stable/pdfplus/1241211.pdf $>$ Acesso em: 27 mai. 2009.

ROSE, R. N. Supply shifts and research benefits: comments. American Journal of Agricultural Economics, Agricultural \& Applied Economics Association, v. 63, n. 2, p. 834-837, 1980. Disponível em: <http://www.jstor.org/stable/1239793 > Acesso em: 27 mai. 2009.

SANTANA, A. C.; KHAN, A. S. Custo social da depredação florestal no Pará: o caso da castanha-dobrasil. Revista de Economia e Sociologia Rural, Brasília, v. 30, n. 3, p. 253-269, 1992.

SILVA, I. M.; SANTANA, A. C.; REIS, M. S. Análise dos retornos sociais oriundos de adoção tecnológica na cultura do açaí no Estado do Pará. Amazônia: Ciência \& Desenvolvimento, Belém, v. 2, n. 3, p. 25-37, 2006.

SILVA, I. M.; SILVA, F. M. Perfil do consumidor domiciliar de açaí na região metropolitana de Belém - PA. In: CONGRESSO DA SOBER, 44., 2006, 
Fortaleza. Anais... Fortaleza: Sociedade Brasileira de Economia e Sociologia Rural, 2006. p. 1-16. SOUZA, I. F. et al. Organização social dos povos indígenas e sua influencia na estrutura de mercado de castanha-do-brasil: o caso da comunidade indígena Rikbaktsa. In: CONGRESSO DA SOCIEDADE BRASILEIRA DE ECONOMIA,
ADMINISTRAÇÃO E SOCIOLOGIA RURAL, 2008, Rio Branco. Disponível em: <http://www. sober.org.br/palestra/9/835.pdf $>$ Acesso em: 19 jan. 2010.

TONINI, H. Castanheira-do-brasil: uma espécie chave na promoção do desenvolvimento com conservação. Boa Vista: EMBRAPA, 2007. 3 p. 